\title{
Cloning and Nucleotide Sequence of Thermostable Lipase Gene from Pseudomonas fluorescens SIK W1
}

\author{
Guk Hoon Chung, Young Phil Lee, Gwang Ho JEoHn, \\ Ook Joon Yoo, and Joon Shick RHEE ${ }^{\dagger}$ \\ Department of Biological Science and Engineering Korea Advanced Institute of Science and Technology, \\ P.O. Box 150, Chongyang, Seoul 130-650, Korea
}

Received March 22, 1991

\begin{abstract}
A gene coding for a thermostable lipase of Pseudomonas fuorescens SIK W1 was cloned into Escherichia coli JM83 by inserting Sau3AI-generated DNA fragments into the BamHI site of pUC19. Twenty colonies with esterase activity on the tributyrin agar plate were isolated by screening the constructed Pseudomonas fuorescens genomic library. Only one out of the esterase positive 20 colonies had lipase activity on the agar plate containing olive oil and Rhodamine-B.

The complete nucleotide sequence of the lipase gene was identified. The lipase gene consists of an open reading frame, $1347 \mathrm{bp}$ long, commencing with an ATG start codon encoding a polypeptide of 449 amino acid residues and a TGA stop codon. Comparison of this lipase amino acid sequence with those from another organisms sequenced to data showed the presence of the short homologous region Gly-X-Ser-X-Gly.
\end{abstract}

Lipases (triacylglycerol acylhydrolase, EC 3.1.1.3) are widely distributed in animals, plants, and microorganisms (fungi and bacteria). Microbial lipases have commercial potentials in lipase-catalyzed triglyceride hydrolysis, interesterification, and other areas of interest such as energy saving process. ${ }^{11}$

Recently molecular clonings of some lipase genes have been reported and the primary structures of those lipases were identified. ${ }^{2-12)}$ Cloning and sequence analysis of the lipase gene is expected to allow the understanding of the relationship between the function and the structure of lipase, and mass production of the enzyme. The enzymes that are cloned to date, however, are mostly not thermostable. Thus their industrial usages are somewhat limited.

Thermostable lipases that are produced by a psychrotrophic bacterium, Pseudomonas fluorescens, are a major concern during storage of heat-processed, commercially sterile foods. ${ }^{13-15)}$ Andersson et al. ${ }^{13)}$ reported that the crude lipase from $P$. fluorescens SIK W1 is not only heat stable but also highly stable against chemical denaturants. Though the presence of lipase activity associated with this microorganism has been studied well in the view of heat-sterilization and deactivation of the lipase for long-term storage of foods, ${ }^{13-16)}$ there are few reports which deal with molecular structures of the lipase gene from this microorganism.

We have cloned and sequenced the nucleotides of the thermostable lipase gene from $P$. fluorescens SIK W1, and previously reported the overexpression of the lipase gene in Escherichia coli and renaturation into biologically active form. ${ }^{17)}$

This study deals with the molecular cloning and nucleotide sequence of the lipase gene from $P$. fluorescens SIK W1 in E. coli.

\section{Materials and Methods}

Bacterial strains, plasmids, and media. P. fuorescens SIK Wl was kindly supplied to us by Dr. Andersson (SIK-The

$\uparrow$ To whom correspondence should be addressed. 
Swedish Food Institute, Sweden) and used as the source of DNA for cloning. Plasmid pUC19 harboring ampicillin resistance was used as a vector. E. coli JM83 was used as the host for recombinant plasmids. E. coli was grown in LB medium at $37^{\circ} \mathrm{C}$ and $P$. fuorescens was grown in nutrient broth at $25^{\circ} \mathrm{C}$.

Recombinant DNA techniques. Chromosomal DNA was isolated from $P$. fluorescens by a modification of the method of Marmur ${ }^{18)}$ and plasmid DNA was prepared from E. coli JM83 cells by $\mathrm{CsCl}-\mathrm{EtBr}$ equilibrium centrifugation of the cleared lysates as described by Maniatis et al. ${ }^{19)}$ For the rapid isolation of plasmids from the bacterial culture, the alkaline lysis method described by Birnboim and Doly was used. ${ }^{20)}$

The genomic library of $P$. fuorescens DNA was constructed by the method described by Choi et al. ${ }^{21)} E$. coli JM83 competent cells were prepared by the method of Hanahan. ${ }^{22}$

Screening for lipase producing E. coli. The tributyrin diffusion agar method was used to find the colonies with activities of carboxylic ester hydrolyzing enzyme (EC 3.1.1) as discribed by Kugimiya et al. ${ }^{2)}$ To distinguish the colonies with lipase activity from carboxylester hydrolase activity, olive oil agar containing Rhodamine-B was used by the method of Kouker et al. ${ }^{23)}$ E. coli JM83 transformed with a DNA library of $P$. fluorescens was grown on LB-agar plates containing ampicillin $(50 \mu \mathrm{g} / \mathrm{ml})$ and emulsified tributyrin at $37^{\circ} \mathrm{C}$ for $24 \mathrm{hr}$. The colonies with clear haloes on the tributyrin agar plate were transferred onto the nutrient agar containing olive oil $(1 \%, v / v)$ and Rhodamine-B $(0.001 \%, w / v)$. Lipolytic activity was detected as a fluorescent zone around the colony when the plate was examined on a UV transilluminator.

Nucleotide sequencing. The nucleotides of the DNA fragment containing the cloned lipase gene were sequenced in both directions by the dideoxy chain termination method of Sanger et al. ${ }^{24)}$ Recombinant M13mp 18 and M13mpl9 phage were used for preparation of single stranded DNAs for nucleotide sequencing. ${ }^{25}$

Chemicals and enzymes. Sau3AI and calf intestinal alkaline phosphatase were purchased from Promega Biotech. Co. (U.S.A.) and T4-DNA ligase and all restriction endonucleases were purchased from either KOSCO Biotechnology Labs (Seongnam, Korea) or New England Biolabs, Inc. (Beverly, MA, U.S.A.). Restriction digestions and ligation reactions were done by the manufacture's recommendation. $\left[\alpha-{ }^{35} \mathrm{~S}\right] \mathrm{dATP}$ was purchased from Amersham (Buckinghamshire, UK). All other chemicals were of analytical reagent grade.

\section{Results and Discussion}

\section{Cloning of the lipase gene from P. fluorescens}

Chromosomal DNA from $P$. futorescens was partially digested with the restriction enzyme Sau3AI. The digested DNA was isolated by sucrose gradient centrifugation and the fragments of about 4 to $20 \mathrm{~kb}$ were used for cloning. The pUC19 plasmid DNA was cut with BamHI and dephosphorylated with calf intestinal alkaline phosphatase. The linearized plasmid DNA was ligated to the $P$. fluorescens DNA fragments and resulting recombinant plasmids were used to transform E. coli JM83. To select the colonies with esterase activity including lipase activity, about 12,000 recombinant colonies were screened on tributyrin agar plates. Twenty colonies appeared to show esterase activity, which was proven by a clear halo on tributyrin plates. They could be divided into four groups after mapping the plasmids with various restriction enzymes. To isolate the bacterial clones carrying the lipase gene from these colonies, these were transferred onto the olive oil agar plates containing Rhodamine-B. Only one colony had the lipase activity and formed an orange fluorescent zone around the colony on a UV transilluminator. The plasmid with an insert of a 10.3-kb DNA fragment was isolated from the

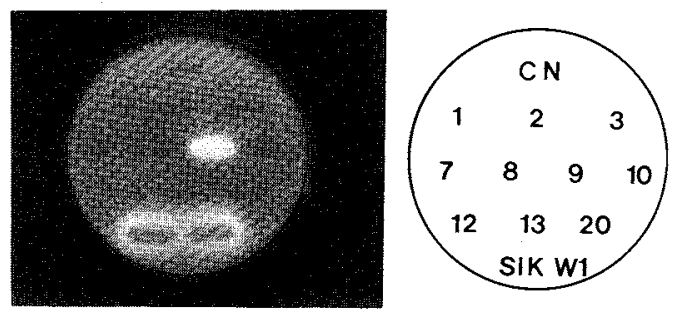

Fig. 1. The Screening of E. coli for Lipase Activity.

All the esterase positive clones were transferred on nutrient broth agar containing olive oil $(1 \%, \mathrm{v} / \mathrm{v})$ and Rhodamine-B $(0.001 \%$, w/v). After incubation for $48 \mathrm{hr}$ at $37^{\circ} \mathrm{C}$, the plate was irradiated with UV $(350 \mathrm{~nm})$ and photographed. Numbers represent $E$. coli strains carrying the esterase gene from $P$. fluorescens. $P$. fluorescens SIK Wl and a strain (No. 9) of E. coli transformants formed orange fluorescent halos around the colonies, indicating production of lipase. $\mathrm{CN}$, control strain E. coli JM83 (pUCI9); SIK W1, P. fuorescens SIK W1. 


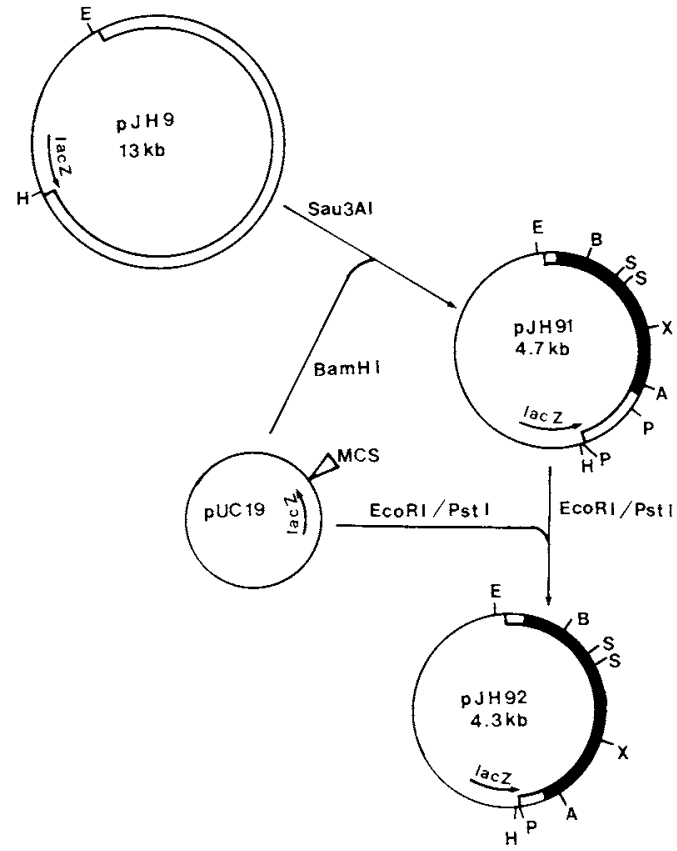

Fig. 2. Construction of the Recombinant Plasmid pJH92.

The plasmid (pJH9) carrying a 10.3-kb Sau3AI fragment originating from $P$. fluorescens was digested by $E c o$ RI and HindIII and used for a series of subcloning experiments as described in the text. The thick line represents the lipase gene. Abbreviations for the restriction sites are as follows: E, EcoRI; H, HindIII; P, PstI; B, BalI; X, XhoI; S, SalI; $\mathrm{A}, A c c \mathrm{I}$.

clone and named pJH9. Figure 1 shows that the lipases are produced by both $E$. coli JM83 harboring pJH9 and $P$. fluorescens.

The resultant recombinant plasmid (pJH9) carrying lipase gene has about a $10.3-\mathrm{kb}$ insert of Pseudomonas DNA. The insert DNA fragment of pJH9 was partially digested with Sau3AI and 1-2kb DNA fragments were eluted on $1.2 \%$ agarose gel. The resultant DNA fragments were ligated into the $B a m \mathrm{HI}$ site of pUC19. When used to transform E. coli JM83, we obtained the lipase-positive colonies having the 2.0-kb DNA insert on pUC19. The plasmid was named pJH91, and after deletion of a 400-bp PstI fragment of pJH91, the nucleotides of the resultant plasmid designated pJH92 were sequenced. Figure 2 shows the subcloning strategy of the lipase gene.

\section{Primary structure of the lipase}

The nucleotide sequence of the inserted DNA of pJH92 was analyzed by Sanger's dideoxy chain termination method. The 1595 base pair nucleotide sequence that contains the entire lipase gene is shown in Fig. 3. Assignment of the open reading frame was done on the basis of $\mathrm{N}$-terminal amino acid sequencing and the molecular weight of the lipase which was measured by SDS-polyacrylamide gel electrophoresis. The molecular weight of the lipase was calculated to be 48,179 (including the initiator, Met) from the predicted amino acid composition. The molecular weight of lipase measured by $9 \%$ SDS-polyacrylamide gel electrophoresis was estimated as 52,000 , which was slightly different from that by the predicted amino acid composition. An open reading frame (154-1500) commencing with an ATG start codon encoding 449 amino acid residues and a TGA stop codon was found in this nucleotide sequence. A homologous region found in all the lipases sequenced to data appeared at amino acid residues 199-209, which was regarded as a substrate binding site of the lipase and also conformed the correct open reading frame. The $\mathrm{N}$-terminal amino acid sequences of the partial purified lipase which was overproduced from the recombinant $E$. coli $^{17)}$ were analyzed to obtain the experimental evidence that supports the idea that the open reading frame encodes the lipase. The results of Edman degradation up to 13 cycles (by a protein sequanator, Applied Biosystem, model 471A) agreed with the predicted amino acid sequence of the lipase. Upstream from ATG of the lipase gene, there is a $5^{\prime}$-GAGA-3' sequence that might function as a Shine-Dalgarno (SD) sequence ${ }^{26)}$ and this sequence coincided with that of the $P$. frag $i$ lipase gene. ${ }^{2)}$

The extent of expression of the lipase gene in $E$. coli was dependent on the orientation of the inserted DNA in the vector and controlled by the external vector promoter. Though a putative promoter region that resembles the consensus sequences of $E$. coli promoters could not be found, weak enzyme activity was 
154 ATG GGT GTA TTT GAC TAC AAG AAC CTC GGC ACC GAA GCC AGC AAA ACC TTG TTC GCC GAT GCC ACC GCA ATC

1 Met Giy Val Phe Asp Tyr Lys Asn Lou Gly Ihr Glu. Ala Ser Lys Thr Leu Phe Ala Asp Ala Thr Ala I Te

226 ACG TTG TAT ACC TAT CAC AAC CTG GAT AAC GGC TTC GCA GTC GGC TAC CAG CAA CAT GGC TTG GGG CTC GGC 25 Thr leu Tyr Thr Tyr His Asn Leu Asp Asn Giy Phe Ala Val Giy Tyr Gin Gin His Giy Leu Giy Leu Giy

298 TGC CGG CAC ACT GGT CGG GGC GTT GCT CGG CAG CAC AGA CTC CCA GGG AGT GAT CCC CCG GCA TTC CCT GGA 49 Cys Arg His Thr Gly Arg Gly Val Ala Arg Gin His Arg Leu Pro Gly Ser Asp Pro Pro Ala Phe Pro Gly

370 ATC CTG ACT CGG AAA AGG CCG CCC TGG ACG GGG TGC ACG CAG CGG GTT GGA CGC CAA TCA AGC GCC AGC GCA 73 Ile Leu Thr arg lys arg pro Pro Trp Thr Arg Cys Thr gin Pro val Gly Arg Gin Ser Ser Ala Ser ala

442 CTG GGC TAC GGC GGC AAG GTG GAT GCG CGG GGC ACT TTT TTT GGC GAG AAG GCC GGC TAC ACC ACG GCC CAG 97 Leu Gly Tyr Gly Gly Lys Val Asp Ala Arg Gly Thr Phe Phe Gly Giu Lys Ala Giy Tyr Thr Thr Ala Gin

514 GCC GAA GTG CTG GGC AAG TAC GAT GAC GCC GGC AAA CTG CTC GAG ATC GGC ATC GGT TTT CGT GGC ACC TCG 121 dia Glu Val Leu Gly Lys Tyr Asp Asp Ala Gly Lys Leu Leu.Glu Ile Gly Ile Gly Phe Arg Gly Thr Ser

586 GGC CCT CGG GAA AGC CTG ATT ACG ACT CCA TGC CGA TCT GGT CAG CGA CCT GCT CGC CGC GCT GGG CCC CAA 145 Gly Pro Arg Glu Ser Leu Ile Thr Thr Pro Cys Arg Ser Gly Gin Arg Pro Ala Arg Arg Ala Gly Pro Gin

658 GGA CTA TGC GAA AAA CTA TGC CGG CGA ACG TTT GGC GGC TTG CTC AAG ACG GTG GCC GAC TAT GCC GGC GCC 169 Gly Leu Cys Glu Lys Leu Cys Arg arg Thr phe Gly Gly Leu Leu Lys Thr Val Ala Asp Tyr Ala Gly Ala

730 CAT GGC CTG AGT GGC AAG GAT GTG CTG GTC AGC GGC CAC AGC CTG GGC GGC CTG GCG GTC AAC AGC ATG GCC 193 His Gly Leu Ser Gly Lys Asp Val Leu Val Ser Gly Hij Ser Leu Gly Gly Leu Ala Val Agn Ser Met Ala

802 GAC CTG AGC ACC AGC AAA TGG GCG GGT TTC TAC AAG GAC GCC AAC TAC CTG GCC TAC GCC TCG CCC ACC CAG 217 Asp Leu Ser Thr Ser Lys Tro Ala Gly Phe Tyr Lys Asp Ala Asn Tyr Leu Ala Tyr Ala Ser Pro Thr Gin

874 AGC GCC GGC GAT AAG GTC CTG AAT ATC GGC TAC GAA AAC GAC CCG GTA TTC CGT GCG CTG GAC GGC TCC ACC 241 Ser Ala Gly Asp Lys Val Leu Asn Ile Giy Tyr Glu Asn Asp Pro Val Phe Arg Ala Leu Asp Giy Ser Thr

946 TTC AAC CTG TCG TCC CTC GGC GTG CAT GAC AAG GCC CAC GAG TCG ACC ACC GAC AAC ATC GTC AGC TTC AAC 265 Phe Agn leu Ser Ser leu Giy Vaj His Asp Lys Ala his Giu Ser Thr Thr Asp Asn Ile Val Ser Phe Asn

1018 GAC CAC TAC GCC TCG ACG TTG TGG AAT GTG CTG CCG TTT TCC ATC GCC AAC CTG TCG ACC TGG GTG TCG CAT 289 Asp His Tyr Ala Ser Thr Leu Trp Asn Val leu Pro Phe Ser Ile Ala Asn Leu Ser Thr Trp Val Ser His

1090 TTG CCC AGC GCT TAC GGC GAC GGC ATG ACG CGT GTG CTG GAA TCG GGG TTC TAC GAG CAA ATG ACC CGT GAC 313 Leu Pro Ser Ala Tyr Gly Asp Gly Met Thr Arg Val Leu Giu Ser Gly Phe Tyr Glu Gln Met Thr Arg Asp

1182 TCG ACG ATT ATC CTG TGC CCA ACC TGG TCC GAC CCG GCG CGC GCC AAC ACC TGG GTC CAG GAC CTC AAC CGC 337 Ser Thr Ile Ile Leu Cys Pro Thr Trp Ser Asp Pro Ala Arg Ala Asn Thr Trp Val Gin Asp Leu Asn Arg

1234 AAT GCC GAG CCG CAC ACA GGC AAT ACC TTC ATC ATC GGC AGC GAC GGC AAT GAC CTG ATC CAG GGC GGC AAG 361 Asn Ala Glu Pro His Thr Gly Asn Thr Phe Ile Ile Gly Ser Asp Giy Asn Asp Leu Ile Gin Giy Giy Lys

1306 GGC GCG GAC TTC ATC GAA GGC GGC AAG GGC AAT GAC ACG ATC CGC GAC AAC AGC GGG CAC AAC ACC ITT TTG 385 Giy ATa Asp Phe I le Glu Giy Gly Lys Gly Asn Asp Thr Ile Arg Asp Asn Ser Gly His Asn Thr Phe Leu

1378 TTC AGC GGG CAT TTT GGC CAG GAT CGG ATT ATC GGC TAC CAG CCG ACA GGC TGG TGT TCC AGG GCG CCG ACG 409 Phe Ser Gly His Phe Gly Gin Asp Arg Ile Ile Gly Tyr Gin pro Thr Gly Trp Cys Ser Arg Ala Pro Thr

1450 GCA GCA CCG ACC TGC GCG ACC ACG CGA AGG CCG TGG GGG CCG ATA CGG TGC TGA

433 Ala Ala Pro Thr Cys Ala Thr Thr Arg Arg Pro Tro Gly Pro Ile Arg Cys *k*

GITTTGGCGCCGACTCGGT

1523 GACCTGGTCGGGGTCGGGCTGGGCGGCCTGTGGAGCGAGGGTGTGCTGATCCCCGGGTACCGAGCTCGAATTC

ECORI

Fig. 3. The Nucleotide Sequence of the Lipase Gene and the Deduced Amino Acid Sequence of Lipase.

The total DNA sequence of lipase gene is presented and the deduced amino acid sequence is shown below the DNA sequence. A putative ribosome binding site (SD sequence) is underlined. The substrate binding site is shown by the double underline. The deduced $N$-terminal amino acid sequences, which were confirmed by amino acid sequencing of the lipase (amino acid 1-13), are underlined. The asterisks indicate a stop codon. The putative signal sequence is denoted by the vertical arrow. 
detected when the $1.6-\mathrm{kb}$ fragment was inserted opposite direction in the vector. This result suggests that the promoter of this gene may not function well in $E$. coli and agreed with the report of Bagdasarian and Timmis ${ }^{27)}$ that the promoter of Pseudomonas did not function well in E. coli.

The leader sequence, which was composed of a positively charged amino acid at its N-terminal end followed by a hydrophobic domain is a characteristic structure of secreted proteins. The amino acid sequence deduced from the nucleotide sequence of the lipase had a putative signal sequence containing 23 amino

Table I. CODON USAGE FOR THE LIPASE GENE OF P. fluorescens

\begin{tabular}{|c|c|c|c|c|c|}
\hline aa & Codon & No. & aa & Codon & No. \\
\hline \multirow[t]{6}{*}{ Arg } & $\mathrm{CGU}$ & 4 & Val & GUU & 2 \\
\hline & $\mathrm{CGC}$ & 6 & & GUC & 6 \\
\hline & CGA & 4 & & GUA & 2 \\
\hline & CGG & 10 & & GUG & 8 \\
\hline & $\mathrm{AGA}$ & 1 & Lys & AAA & 5 \\
\hline & $\mathrm{AGG}$ & 3 & & AAG & 11 \\
\hline \multirow[t]{6}{*}{ Leu } & CUU & 0 & Asn & AAU & 6 \\
\hline & CUC & 7 & & $\mathrm{AAC}$ & 14 \\
\hline & CUA & 2 & Gin & CAA & 4 \\
\hline & CUG & 20 & & CAG & 10 \\
\hline & UUA & 0 & His & $\mathrm{CAU}$ & 5 \\
\hline & UUG & 7 & & CAC & 8 \\
\hline \multirow[t]{6}{*}{ Ser } & UCU & 1 & Glu & GAA & 7 \\
\hline & UCC & 5 & & GAG & 5 \\
\hline & UCA & I & Asp & GAU & 8 \\
\hline & UCG & 9 & & GAC & 19 \\
\hline & $\mathrm{AGU}$ & 2 & Tyr & UAU & 3 \\
\hline & $\mathrm{AGC}$ & 15 & & UAC & 13 \\
\hline \multirow[t]{4}{*}{ Thr } & $\mathrm{ACU}$ & 4 & Cys & UGU & 1 \\
\hline & $\mathrm{ACC}$ & 19 & & UGC & 8 \\
\hline & $\mathrm{ACA}$ & 2 & Phe & UUU & 8 \\
\hline & ACG & 13 & & UUC & 11 \\
\hline \multirow[t]{4}{*}{ Pro } & $\mathrm{CCU}$ & 3 & Ile & AUU & 3 \\
\hline & $\mathrm{CCC}$ & 5 & & AUC & 14 \\
\hline & $\mathrm{CCA}$ & 3 & & AUA & 1 \\
\hline & $\mathrm{CCG}$ & 12 & Met & AUG & 4 \\
\hline \multirow[t]{4}{*}{ Ala } & GCU & 4 & Trp & UGG & 8 \\
\hline & GCC & 21 & & & \\
\hline & GCA & 6 & & & \\
\hline & GCG & 8 & & & \\
\hline \multirow[t]{4}{*}{ Gly } & GGU & 5 & & & \\
\hline & $\mathrm{GGC}$ & 43 & & & \\
\hline & GGA & 3 & & & \\
\hline & GGG & 7 & & & \\
\hline
\end{tabular}

acids with the classical characteristics of a hydrophilic region followed by hydrophobic amino acid ending in Ala-X-Ala before the mature protein. ${ }^{28)}$

Nucleotide content and codon usage of the lipase

Analysis of the sense strand of the open reading frame for the lipase gene of $P$. ftuorscens showed a $\mathrm{G}+\mathrm{C}$ content of $62.5 \%$ which correlated with the value of $60-63 \%$ observed from chromosomal DNA of $P$. fluorescens. ${ }^{29)}$ The $\mathrm{G}+\mathrm{C}$ contents of the $P$. fluorescens lipase gene in the first and second positions of codons were 57.1 and $52.7 \%$, respectively. There was a predominance of codons with $\mathrm{G}$ or $\mathrm{C}$ in the third position in the $P$. fluorescens gene such that the $\mathrm{G}+\mathrm{C}$ content in position $3,77.7 \%$, was even higher than that of the entire gene (Table I). Preference for G or $\mathrm{C}$ at the third position has been observed in other sequenced genes of Pseudomonas. Minton et al. ${ }^{30)}$ reported that the codon bias in the codon usage of Pseudomonas forwards codons ending in $\mathrm{G}$ or $\mathrm{C}$ conferred on the gene

Table II. A CONSERVEd SEQUENCE AMONG LiPOLYTIC ENZYMES

Lipase $\begin{gathered}\text { Substrate } \\ \text { binding site }\end{gathered}$

\begin{tabular}{|c|c|c|}
\hline \multicolumn{3}{|l|}{ Microorganisms } \\
\hline $\begin{array}{l}\text { Pseudomonas } \\
\text { fragi }\end{array}$ & $\stackrel{76}{R V N L I G H S Q G A}^{86}$ & 2 \\
\hline $\begin{array}{l}\text { Staphylococcus } \\
\text { aureus }\end{array}$ & $\stackrel{405}{\text { KVHLVGHSMGG }} \stackrel{415}{ }$ & 3 \\
\hline $\begin{array}{l}\text { Staphylococcus } \\
\text { hyicus }\end{array}$ & $\stackrel{362}{\text { PVHFIGHSMGG }} \stackrel{372}{ }$ & 4 \\
\hline $\begin{array}{l}\text { Rhizomucor } \\
\text { miehei }\end{array}$ & $\stackrel{137}{\text { KVAVTGHSLGG }^{147}}$ & 5 \\
\hline $\begin{array}{l}\text { Pseudomonas } \\
\text { fluorescens }\end{array}$ & $\stackrel{199}{\text { DVLVSGHSLGG }}$ & This study \\
\hline Animals & & \\
\hline $\begin{array}{l}\text { Rat hepatic } \\
\text { lipase }\end{array}$ & $\stackrel{140}{\text { KVHLIGYSLGA }} \stackrel{150}{ }$ & 6 \\
\hline $\begin{array}{l}\text { Human hepatic } \\
\text { lipase }\end{array}$ & $\stackrel{138}{\text { HVHLIGYSLGA }}$ & 7 \\
\hline $\begin{array}{l}\text { Bovine lipoprotein } \\
\text { lipase }\end{array}$ & $\stackrel{127}{\text { NVHLLGYSLGA }}{ }^{137}$ & 8 \\
\hline $\begin{array}{l}\text { Porcine pancreatic } \\
\text { lipase }\end{array}$ & $\stackrel{145}{\text { NVHVIGHSLGS }} \stackrel{155}{ }$ & 9 \\
\hline $\begin{array}{l}\text { Human lipoprotein } \\
\text { lipase }\end{array}$ & ${ }^{125}$ NVHLLGYSLGA & 10 \\
\hline
\end{tabular}




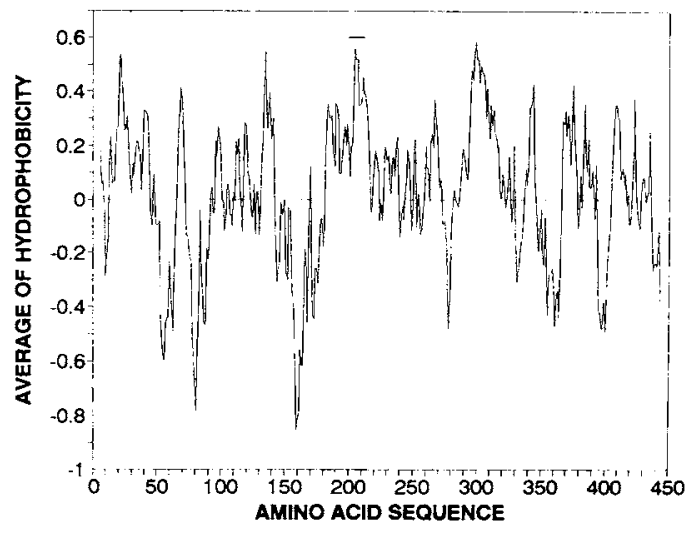

Fig. 4. Hydrophobicity Profile for the Lipase from $P$. fuorescens.

Hydrophobicity profile for the total amino acids of lipase was calculated by the method of Eigenberg ${ }^{32}$ with a window of six. The thick bar indicates the substratebinding region of the lipase.

some properties normally associated with weakly expressing $E$. coli genes and might therefore contribute to the overall low expression of Pseudomonas genes in E. coli.

\section{Structural features of the P. fluorescens lipase}

Lipases are characterized by the ability to preferably catalyze the hydrolysis of ester bonds at the interface between the water-insoluble fat phase and the aqueous phase in which the enzyme is soluble. Lipase sequences from several procaryotic ${ }^{2-5)}$ and eucaryotic ${ }^{6-12)}$ organisms all contain a Gly-X-Ser-X-Gly sequence, which was reported to be a part of the interfacial lipid recognition site by Guidoni et al. ${ }^{31)}$ Table II shows the conserved sequence among lipases. The homologous region [AspVal-Leu-Val-Ser-Gly-His-Ser-Leu-Gly-Gly] was found in $P$. fluorescens lipase, too. A hydrophobicity plot of the lipase, constructed as described by Eigenberg, ${ }^{32)}$ indicates that this substrate binding site of the lipase is in a highly hydrophobic domain (Fig. 4). All sequenced lipases except those from $P$. fragi and Rhizomucor miehei have presence of potential glycosylation sites. ${ }^{33)}$ The amino acid sequence of the $P$. fluorescens lipase predicted from nucleotide sequence of the lipase gene also contains three potential sites $\left[\mathrm{Asn}-\mathrm{X}_{\mathrm{a}}\right.$ -
(Thr/Ser)] for N-linked glycosylation at amono acid residues 266-268, 305-307, and 395-397.

In this paper we described the cloning and nucleotide sequence of the thermostable lipase gene from $P$. fluorescens in $E$. coli. To isolate a specific gene from the gene donor by shot-gun cloning, a screening method for the recombinant colony is very important. An agar plate containing tributyrin or Tween 80 as a substrate is frequently used for screening of lipases. When tributyrin was used for the screening for a lipase producer from the $P$. fuorescens genomic library, twenty colonies with esterase activity were isolated. This implies that substrates such as tributyrin or Tween 80 are not suitable to detect true lipases because they can be hydrolyzed by esterases, too. Therefore for the screening of recombinant colonies with lipase activity we used the method described by Kouker and Jaeger, which is a plate assay method for detection of lipase in a medium containing the fluorescent dye, Rhodamine- $\mathrm{B}$, and olive oil as a true substrate of lipases.

We reported in our previous paper that the thermostable lipase using this cloned lipase gene was overproduced in $E$. coli BL21 as inclusion bodies. ${ }^{17)}$ They were refolded into a biologically active form and the lipase showed high thermostability; the time required for $90 \%$ inactivation of the enzyme was $4 \mathrm{hr}$ at $95^{\circ} \mathrm{C}$. The lipase gene had a polypeptide containing nine Cys residues, which might participate in the formation of disulfide bridge. Further research should be done for the elucidation of possible contributions of disulfide bonds to the extreme thermostability of the $P$. fluorescens lipase. Several thermostable lipases from thermostable fungi such as Humicola lanuginosa ${ }^{34)}$ and from the genus Pseudomonas such as P. fluorescens, ${ }^{35)}$ Pseudomonas sp. KWI-56, ${ }^{36)}$ and $P$. fragi ${ }^{37)}$ have been reported. The use of the thermostable microbial lipases in the oleochemical industry may provide advantages of decreased fluid viscosity and increased lipid solubility at high temperature. Furthermore, the operation stability of enzyme reactors at high temperatures 
may be increased.

\section{References}

1) T. Yamane, "Proceedings of World Conference on Biotechnology for the Fats and Oils Industry," American Oil Chemists' Society, 1988, pp. 17-22.

2) W. Kugimiya, Y. Otani, Y. Hashimoto and Y. Takagi, Biochem. Biophys. Res. Commun., 141, 185 (1986).

3) C. Y. Lee and J. J. Iandolo, J. Bacteriol., 166, 385 (1986).

4) F. Gotz, F. Popp, E. Korn and K. H. Schleifer, Nucleic Acids Res., 13, 5895 (1985).

5) E. Boel, B. Huge-Jensen, M. Christensen, L. Thim and N. P. Fiil, Lipids, 23, 701 (1988).

6) M. C. Komaromy and M. C. Schotz, Proc. Natl. Acad. Sci. U.S.A., 84, 1526 (1987).

7) G. Stahnke, R. Sprengel, J. Augustin and H. Will, Differentiation, 35, 45 (1987).

8) M. Senda, K. Oka, W. V. Brown, P. K. Qasba and Y. Furuichi, Proc. Natl. Acad. Sci. U.S.A., 84, 4369 (1987).

9) J. De Caro, M. Boudouard, J. Bonicel, A. Guidoni, P. Desnuelle and M. Rovery, Biochim. Biophys. Acta, 671, 129 (1981).

10) K. L. Wion, T. G. Kirchgessner, A. J. Lusis, M. C. Schotz and R. M. Lawn, Science, 235, 1638 (1987).

11) L. Brady, A. M. Brzozowski, Z. S. Derewenda, E. Donson, G. Donson, S. Tolley, J. P. Turkenburg, L. Christiansen, B. H. Jensen, L. Norskov, L. Thim and U. Menge, Nature, 343, 767 (1990).

12) F. K. Winkler, A. D'Arcy and W. Hunziker, Nature, 343, 771 (1990).

13) R. E. Andersson, C. B. Hedlund and U. Jonsson, J. Dairy Sci, 62, 361 (1979).

14) D. M. Adams and T. G. Brawley, J. Dairy Sci., 64, 1951 (1981).

15) F.W. Driessen and J. Stadhouders, Food Sci. Technol. Abstr., 6, 130 (1973).

16) R. E. Andersson, G. Danielsson, C. B. Hedlund and
S. G. Svensson, J. Dairy Sci., 64, 375 (1981).

17) G. H. Chung, Y. P. Lee, O. J. Yoo and J. S. Rhee, Appl. Microbiol. Biotechnol., 35, 237 (1991).

18) J. Marmur, J. Mol. Biol., 3, 208 (1961).

19) T. Maniatis, E. F. Fritich and J. Sambrook, "Molecular Cloning: A Laboratory Manual," Cold Spring Harbor, N.Y., 1982.

20) H. C. Birnboim and J. Doly, Nucl. Acids Res., 7, 1515 (1979).

21) K. D. Choi, G. H. Jeohn, J. S. Rhee and O. J. Yoo, Agric. Biol. Chem., 54, 2039 (1990).

22) D. Hanahan, J. Mol. Biol., 166, 557 (1983).

23) G. Kouker and K. E. Jaeger, Appl. Environ. Microbiol., 53, 211 (1987).

24) F. Sanger, S. Nicklen and A. R. Coulson, Proc. Natl. Acad. Sci. U.S.A., 74, 5463 (1977).

25) J. Norrander, T. Kempe and J. Messing, Gene, 26 101 (1983).

26) J. Shine and L. Dalgarno, Proc. Natl. Acad. Sci. U.S.A., 71, 1342 (1974).

27) M. Bagdasarian and K. N. Timmis, in "Current Topics in Microbiology and Immunology," Vol. 96, ed. by P. H. Hofschneider and W. Goebel, Springer Verlag, Berlin, 1983, pp. 47-64.

28) M. S. Briggs and L. M. Gierasch, Adv. Protein Chem., 38, 109 (1986).

29) P. D. Vos and J. D. Ley, Int. J. Systematic Bacteriol, 33, 487 (1987).

30) N. P. Minton, T. Atkinson, C. J. Bruton and R. F. Sherwood, Gene, 31, 31 (1984).

31) A. Guidoni, F. Benkouka, J. DeCaro and M. Rovery, Biochim. Biophys. Acta, 660, 148 (1981).

32) D. Eisenberg, Ann. Rev. Biochem., 53, 595 (1984).

33) E. Antonian, Lipids, 23, 1101 (1988).

34) W. H. Liu, T. Beppu and K. Arima, Agric. Biol. Chem., 37, 157 (1972).

35) Y. Kosugi, H. Suzuki and T. Funada, Biotechnol. Bioeng., 31, 349 (1988).

36) T. Iizumi, K. Nakamura and T. Fukase, Agric. Biol. Chem., 54, 1253 (1990).

37) T. Nishio, T. Chikano and M. Kamimura, Agric. Biol. Chem., 51, 181 (1987). 